\title{
Influence of Dynamic Neuromuscular Stabilization Approach on Maximum Kayak Paddling Force
}

\author{
by \\ Pavel Davidek ${ }^{1}$, Ross Andel2,3, Alena Kobesova ${ }^{4}$
}

\begin{abstract}
The purpose of this study was to examine the effect of Dynamic Neuromuscular Stabilization (DNS) exercise on maximum paddling force (PF) and self-reported pain perception in the shoulder girdle area in flatwater kayakers. Twenty male flatwater kayakers from a local club (age $=21.9 \pm 2.4$ years, body height $=185.1 \pm 7.9 \mathrm{~cm}$, body mass $=$ $83.9 \pm 9.1 \mathrm{~kg}$ ) were randomly assigned to the intervention or control groups. During the 6-week study, subjects from both groups performed standard off-season training. Additionally, the intervention group engaged in a DNS-based core stabilization exercise program (quadruped exercise, side sitting exercise, sitting exercise and squat exercise) after each standard training session. Using a kayak ergometer, the maximum PF stroke was measured four times during the six weeks. All subjects completed the Disabilities of the Arm, Shoulder and Hand (DASH) questionnaire before and after the 6-week interval to evaluate subjective pain perception in the shoulder girdle area. Initially, no significant differences in maximum PF and the DASH questionnaire were identified between the two groups. Repeated measures analysis of variance indicated that the experimental group improved significantly compared to the control group on maximum PF ( $p=.004$; Cohen's $d=.85)$, but not on the DASH questionnaire score $(p=.731)$ during the study. Integration of DNS with traditional flatwater kayak training may significantly increase maximum $P F$, but may not affect pain perception to the same extent.
\end{abstract}

Key words: flatwater kayaking, postural stabilization, pain, strength, ergometer.

\section{Introduction}

Recreational and competitive flatwater kayaking has become a popular activity across the world. With expanded participation at a competitive level, repetitive strain injuries and painful shoulder girdle syndromes (painful upper quarter syndromes) have become more frequent (Fiore and Houston, 2001). Dynamic Neuromuscular Stabilization (DNS) is a manual, rehabilitative and educational approach that may help in repetitive strain injury prevention (Frank et al., 2013). It can be used in the functional treatment of painful musculoskeletal syndromes, but may also enhance athletic performance.

Studies suggest that the most common painful syndromes during a season of competitive flatwater kayaking are the shoulder impingement syndrome, tendinitis of the long head biceps, and herniation of the lumbar disk (Hagemann et al., 2004; Hensel et al., 2008; Pelham et al., 1995). According to Pelham et al. (1995), the cumulative effect of poorly structured resistance training may ultimately result in a painful syndrome called the paddler's shoulder. Different approaches and treatment strategies have been proposed to prevent and treat painful syndromes resulting from the repetitive strain during flatwater

\footnotetext{
1 - Faculty of Physical Education and Sport, Charles University, Prague, Czech Republic.

2 - School of Aging Studies, University of South Florida, Tampa, FL, U.S.A.

3 - International Clinical Research Center, St. Anne's University Hospital, Brno, Czech Republic.

4 - Department of Rehabilitation and Sports Medicine, 2nd Faculty of Medicine, Charles University, University Hospital Motol, Prague, Czech Republic.
} 
kayaking. Common painful syndromes are usually treated by stretching and rotator cuff strengthening exercises (Anderson and Anderson, 2010; Mei-Dan and Carmont, 2013). However, the ultimate goal of a treatment approach should not only consist in getting the kayaker out of current pain, but rather to prevent repetitive strain, increase strength, and promote sport performance (Brolinson et al., 2012).

In this study we used the Kolar's approach to DNS based on neurodevelopmental principles (Kobesova et al., 2014) to identify its effect on painful upper quarter syndromes in flatwater kayakers, and also to determine if integration of DNS within a traditional kayakers' sports training program would affect maximum paddling force (PF). The study is unique in its evidence-based approach to enhancing athletic performance. The DNS approach is based on developmental kinesiology models (Kobesova and Kolar, 2014). DNS encompasses inborn motor patterns or programs that enable the infant to develop an ideal posture, functional joint centration, optimal breathing and locomotion movements throughout ontogenesis. In the DNS approach, the main goal is to restore physiological movement patterns as defined by developmental kinesiology. Optimal quality of trunk stabilization is a basic prerequisite for ideal quality of any movement including sport activities (Kolar and Safarova, 2013). Optimal trunk stabilization is central to effective extremity's muscle activation, allowing for the production of maximal power during athletic performance. Core muscles provide stability that allows for the generation of force and coordinated motion in both the upper and lower extremities, as well as for the distribution of impact forces. Imbalance or deficiencies in the core muscles can result in increased fatigue, decreased endurance and a great risk of athletic injury (Rivera, 2016). Trunk stabilization exercises enhance static and dynamic balance (Imai et al., 2014), improve sport specific movement parameters (Lust et al., 2009; Sharma et al., 2012), and play an important role in sport injury prevention and rehabilitation (Hill and Leiszler, 2011).

In this study we trained competitive kayakers to integrate the DNS strategies within traditional flatwater kayak training to achieve maximum core stability. We hypothesized that intervention with the DNS program would result in improved strength and decreased pain compared to kayaking activity as usual. The effect of this approach on the painful upper quarter syndromes was determined by a pain questionnaire and the effect on PF was measured using a kayak ergometer.

\section{Methods}

\section{Participants}

Twenty male, high performance athletes from a local kayak club participated in the study. These participants would normally train flat water kayaking 5 days per week, which equates to at least $12 \mathrm{~h}$ of physical activity per week. The subjects were randomly assigned to the intervention or control groups. There were no significant differences among the groups in terms of age, body height, body mass, maximum PF or pain as evaluated by the Disabilities of the Arm, Shoulder and Hand (DASH) questionnaire (Fiore and Houston, 2001) $(p>0.05)$. This study was approved by the local Institutional Review Board. A written informed consent form was obtained from all participants.

\section{Measures}

The maximum PF of each kayaker's stroke was measured four times during the 6-week study, at baseline, after 2.5 weeks, after 4 weeks and after 6 weeks (post-test). Participants from both the intervention and the control group were always measured at the same time. In the intervention group, the measurements were taken after the DNS exercise. All measurements were taken on the same Dansprint PRO Kayak ergometer which evaluates the maximum PF in watts (W). The display of a kayak ergometer shows the actual PF and registers the maximal PF. This value was taken from a single kayaking stroke. The maximum PF was obtained first on the left and then on the right side. All subjects performed three trials aiming to achieve the maximum PF during each stroke with a $3 \mathrm{~min}$ rest period between each trial. The final value for each participant was determined by calculating the mean of all trials across both sides. The starting position for the assessment of the maximum PF was the same as the starting position during any flatwater competition. The paddle was held in a "stop" posture and raised to strike. Then the kayaker paddled one stroke with the maximum 
possible power. The DASH questionnaire was completed by all participants at baseline and at six weeks to evaluate the subjective perception of pain in the shoulder girdle area.

\section{Design and Procedures}

The intervention group underwent six weeks of the DNS-based core stabilization exercises during the fall offseason. Every two weeks the participants in the intervention group were individually educated by a physiotherapist to exercise according to the DNS approach. After each standard training session, the participants were instructed by the therapist to perform 20-30 min of DNS based core stabilization training according to the standard DNS protocol. The therapist monitored the quality and duration of exercises and kept track of training sessions for each participant. One therapist supervised all exercise sessions. The therapist ensured that the exercises were performed in a proper manner. The duration and intensity of each DNS exercise session was the same for all participants from the intervention group.

This core stabilization training was prepared specially for flatwater kayakers. For example, the sitting exercise included a position when one tried to straighten the spine, put down the chest to the caudal position, elongate the cervical spine upwards, relax the shoulders and try to breath to the abdomen.

The goal of the DNS approach was to restore the integrated spinal stabilizing system via specific exercises based on the developmental kinesiological positions. In this study, the following developmental positions were used to train the optimal coordination among all muscles stabilizing the trunk: the quadruped exercise (Figure 1), the side sitting exercise (Figure 2), the sitting exercise (Figure 3 ) and the squat exercise (Figure 4).

During the study all subjects from both groups were engaged in their regular flatwater kayak training, consisting mainly of ergometerbased paddling, running, swimming and weightlifting. The intervention and the control groups trained together following the same set of the same standard sport-specific training except for the DNS exercises.

\section{Statistical Analysis}

The significance of the differences in the maximum PF between the intervention and control groups was evaluated using mixed factorial (within-between) repeated measures analysis of variance (ANOVA) with one withinsubject (time: 4 testing sessions) and one betweensubjects (group: DNS intervention vs. control) factor. The analysis yielded main effects for time and group as well as a group-by-time interaction. Our main interest was in the interaction of groupby-time, which reflects the magnitude of the differences in scores between the two groups (i.e., DNS intervention vs. control) that occur over time following the baseline. Therefore, based on our hypothesis, the interaction points to the influence of the intervention on change in performance. Effect sizes were expressed as eta-squared and Cohen's d. When the group-by-time interaction was statistically significant, we proceeded to also present the longitudinal results descriptively by showing the group-based mean scores and standard deviations at each time point, which we evaluated using paired-samples t-tests. Statistical significance was set at a two-tailed 0.05 level. Data were analyzed using Statistica for Windows, version $10 \mathrm{cz}$.

\section{Results}

\section{1) PF results (Table 2 and Figure 5)}

In the mixed factorial repeated measures ANOVA, the main effect of group was not significant $(F[1]=1.16, p=.295)$, confirming that the intervention and control groups were similar in terms of baseline performance. The main effect of time was also not significant $(\mathrm{F}[3]=0.12, p=$ .948 ), suggesting that, overall, changes in performance over time were not statistically significant. There was a significant group-by-time interaction $(\mathrm{F}[3,16]=4.93, p=.010$, partial etasquared $=0.15$, Cohen's $d=0.85$ ), indicating that performance began to vary during the study as a function of group assignment. Specifically, there was a significant increase in the maximum PF over the four measurements in the intervention group when compared to the change in PF over the same four measurements in the control group.

To better illustrate the significant groupby-time interaction, we present means and standard deviations for each group at each of the four time points as well as descriptive statistics to reflect mean differences in scores at each time point. The maximum PF increased in the intervention group (from the baseline mean of 
$239.6 \mathrm{~W} ; \mathrm{SD}=37.5 \mathrm{~W}$ to the mean of $252.7 \mathrm{~W}$ at week 6; $\mathrm{SD}=22.4 \mathrm{~W})$ for a net gain of $13.4 \mathrm{~W}(\mathrm{t}[9]$ $=2.34, p=.044)$. In the control group, a decrease in PF was observed (mean at baseline $=233.2 \mathrm{~W}$; SD $=46.7 \mathrm{~W}$ vs. mean at week $6=216.3 \mathrm{~W}$; $\mathrm{SD}=36.3$; $\mathrm{t}[9]=2.12, p=.063)$. Finally, we also found that the overall gain reflected in the group by time interaction could mainly be attributed to the differences occurring later in the study (Figure 5). Specifically, the differences in PF was particularly salient at week 6 assessment $(p=.032)$, whereas the differences at $2.5(p=.683)$ and 4 weeks $(p=$ .341) did not reach statistical significance.

The overall decline in PF in the control group (7 of the 10 participants declined) was unexpected. To explore this finding, we used the baseline score for each participant in the control group across all four assessments. We found that the group-by-time interaction remained significant $(\mathrm{F}[3,16]=3.79, p=.015$, partial etasquared $=0.03$ [corresponding to Cohen's $\mathrm{d}$ of 0.35]).

\section{2) DASH questionnaire results (Table 3 and Figure 6)}

With respect to the DASH questionnaire, the mixed factorial repeated measures ANOVA indicated that there was a significant overall decrease in DASH scores between week 0 and week $6(\mathrm{~F}[1]=9.35, p=.007)$. However, the groupby-time interaction showed that the change in DASH scores was similar for the intervention and control groups $(\mathrm{F}[1,18]=.12, p=.731)$ (Table 3 and Figure 6).

\begin{tabular}{|c|c|c|c|c|}
\hline \multicolumn{5}{|c|}{ Descriptive Characteristics of Participants } \\
\hline & $\begin{array}{l}\text { All subjects } \\
\qquad(N=20)\end{array}$ & $\begin{array}{l}\text { Intervention group } \\
\qquad(n=10)\end{array}$ & $\begin{array}{l}\text { Control group } \\
\qquad(n=10)\end{array}$ & $p^{\mathrm{a}}$ \\
\hline Age (years) & $21.9 \pm 2.4$ & $22.5 \pm 1.4$ & $21.2 \pm 2.8$ & 0.090 \\
\hline Body height (m) & $185.1 \pm 7.9$ & $1.8 \pm 0.1$ & $1.9 \pm 0.1$ & 0.067 \\
\hline Body mass $(\mathrm{kg})$ & $83.9 \pm 9.1$ & $81.3 \pm 6.2$ & $86.5 \pm 11.9$ & 0.106 \\
\hline Body mass index $\left(\mathrm{kg} / \mathrm{m}^{2}\right)$ & $24.5 \pm 1.7$ & $24.5 \pm 2.3$ & $24.4 \pm 1.8$ & 0.447 \\
\hline $\mathrm{PF}(\mathrm{W})$ & $236.3 \pm 41.9$ & $239.4 \pm 36.1$ & $233.2 \pm 47.6$ & 0.649 \\
\hline DASH score (points) & $18.0 \pm 11.9$ & $15.3 \pm 6.8$ & $20.6 \pm 15.3$ & 0.338 \\
\hline $\begin{array}{r}P F=\text { paddling force, } \\
\text { ap-values are }\end{array}$ & $\begin{array}{l}D A S H=D i \\
\text { based on ine }\end{array}$ & $\begin{array}{l}\text { abilities of the Arm } \\
\text { pendent samples } t\end{array}$ & $\begin{array}{l}\text { Shoulder and } \\
\text { test statistics }\end{array}$ & $n d$ \\
\hline
\end{tabular}


Table 2

Mean and Statistical Difference of the Participant's PF ver Time

\begin{tabular}{|c|c|c|c|c|c|c|c|}
\hline & Maximur & Paddling fo & & & Group & Time & $\begin{array}{c}\text { Group } \\
\text { Time }\end{array}$ \\
\hline & Week 0 & 2.5 weeks & 4 weeks & 6 weeks & $p$ & $p$ & $p$ \\
\hline $\begin{array}{l}\text { Intervention } \\
\text { group } \\
(n=10)\end{array}$ & $\begin{array}{c}239.4 \pm \\
36.5\end{array}$ & $\begin{array}{c}236.9 \pm \\
24.4\end{array}$ & $\begin{array}{c}242.7 \pm \\
27.7\end{array}$ & $\begin{array}{c}252.7 \pm \\
21.8\end{array}$ & & & \\
\hline $\begin{array}{l}\text { Control group } \\
(n=10)\end{array}$ & $\begin{array}{c}233.2 \pm \\
45.5\end{array}$ & $\begin{array}{c}230.3 \pm \\
43.7\end{array}$ & $\begin{array}{c}227.1 \pm \\
37.2\end{array}$ & $\begin{array}{c}216.3 \pm \\
35.3\end{array}$ & 0.295 & 0.947 & 0.004 \\
\hline
\end{tabular}

$P F=$ paddling force, Mean PF is presented with standard deviation

Table 3

Mean and Statistical Difference of the Participant's DASH Score over Time

Disabilities of the Arm, Shoulder and Hand Group $\quad$ Time $\quad \begin{gathered}\text { Group }^{*} \\ \text { Time }\end{gathered}$

\begin{tabular}{rrrrr} 
Week 0 & Week 6 & $p$ & $p$ & $p$ \\
\hline
\end{tabular}

Intervention group

(n= 10) $\quad 15.3 \pm 6.8 \quad 11.7 \pm 4.7$

Control group

\begin{tabular}{llllll}
$(\mathbf{n}=10)$ & $20.6 \pm 15.3$ & $17.7 \pm 14.4$ & 0.226 & 0.007 & 0.731 \\
\hline
\end{tabular}

$D A S H=$ Disabilities of the Arm, Shoulder and Hand,

Mean DASH score is presented with standard deviation 

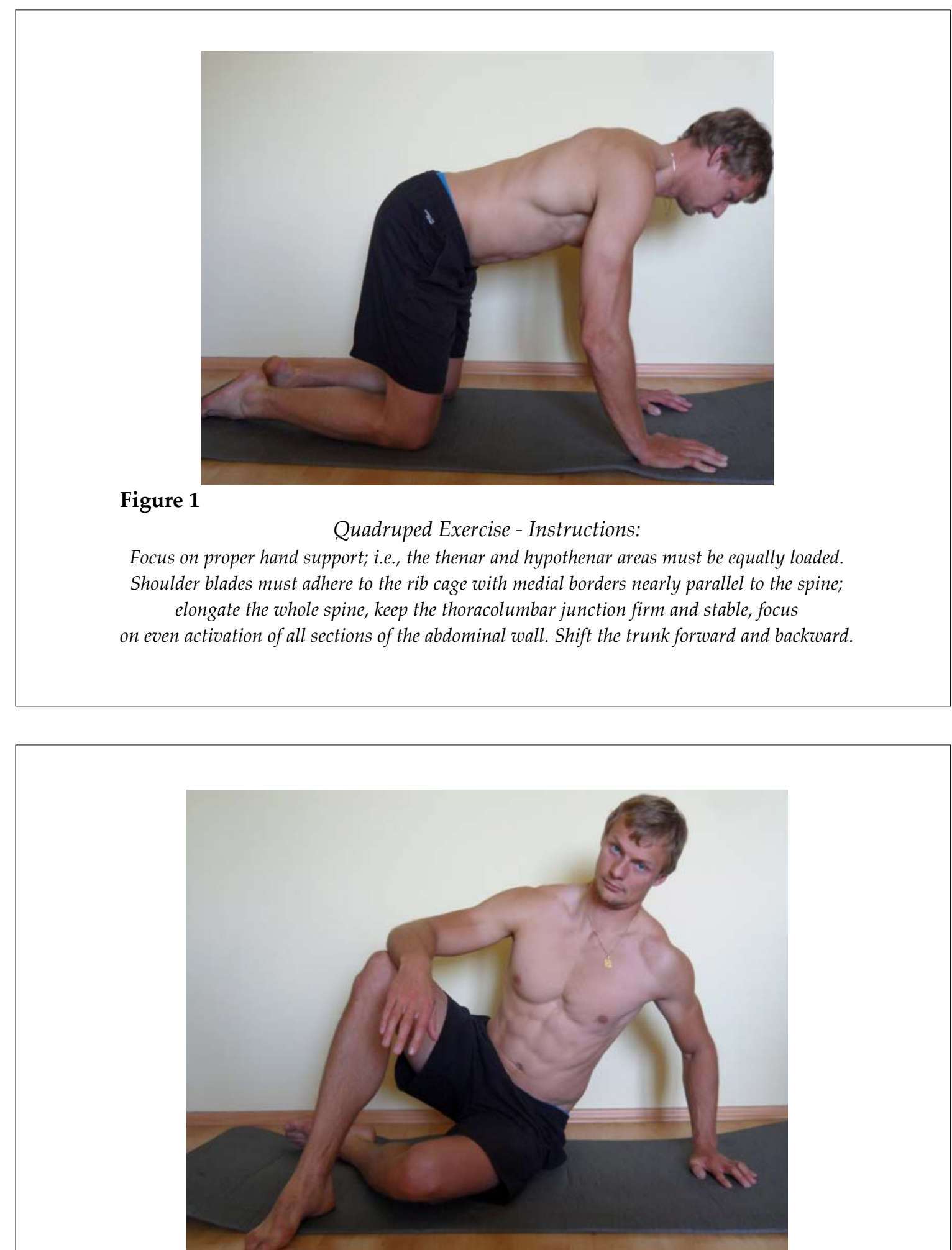

Figure 2

Side Sitting Exercise - Instructions:

Focus on the proportional loading of all parts of the supporting hand, push the supporting hand and the bottom knee to the support, activate (push out) all sections of the abdominal wall, keep the bottom shoulder blade on the rib cage, prevent any scapular winging, elongate the spine. Lift the trunk, hold the position for a few seconds and move back. 

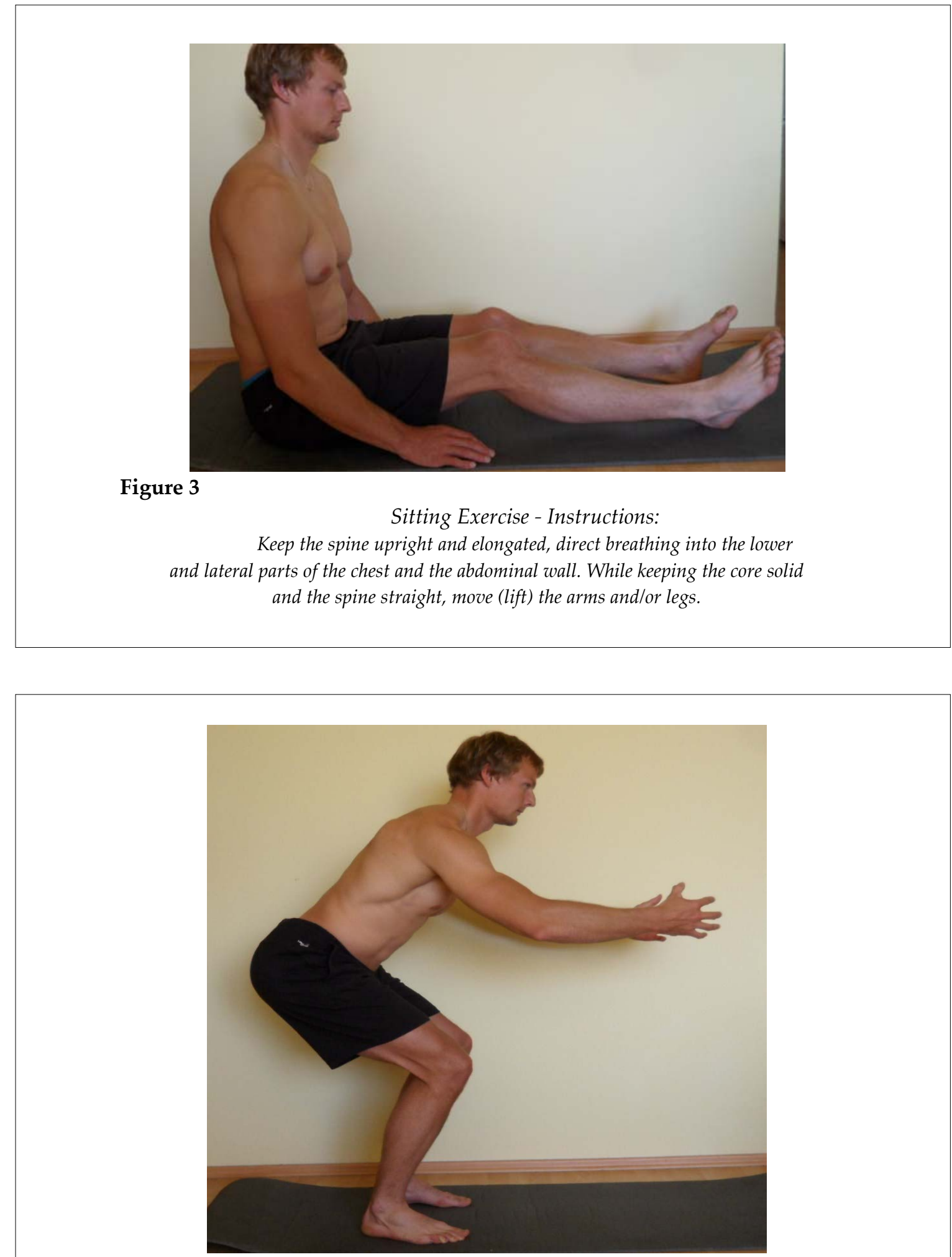

Figure 4

Squat Exercise - Instructions:

Focus on proportional loading of both feet, keep the knees above the forefeet, elongate the spine, pull the shoulder blades caudally, breathe into the groin and dorsolateral sections of the abdominal wall. Move the body up and down. 


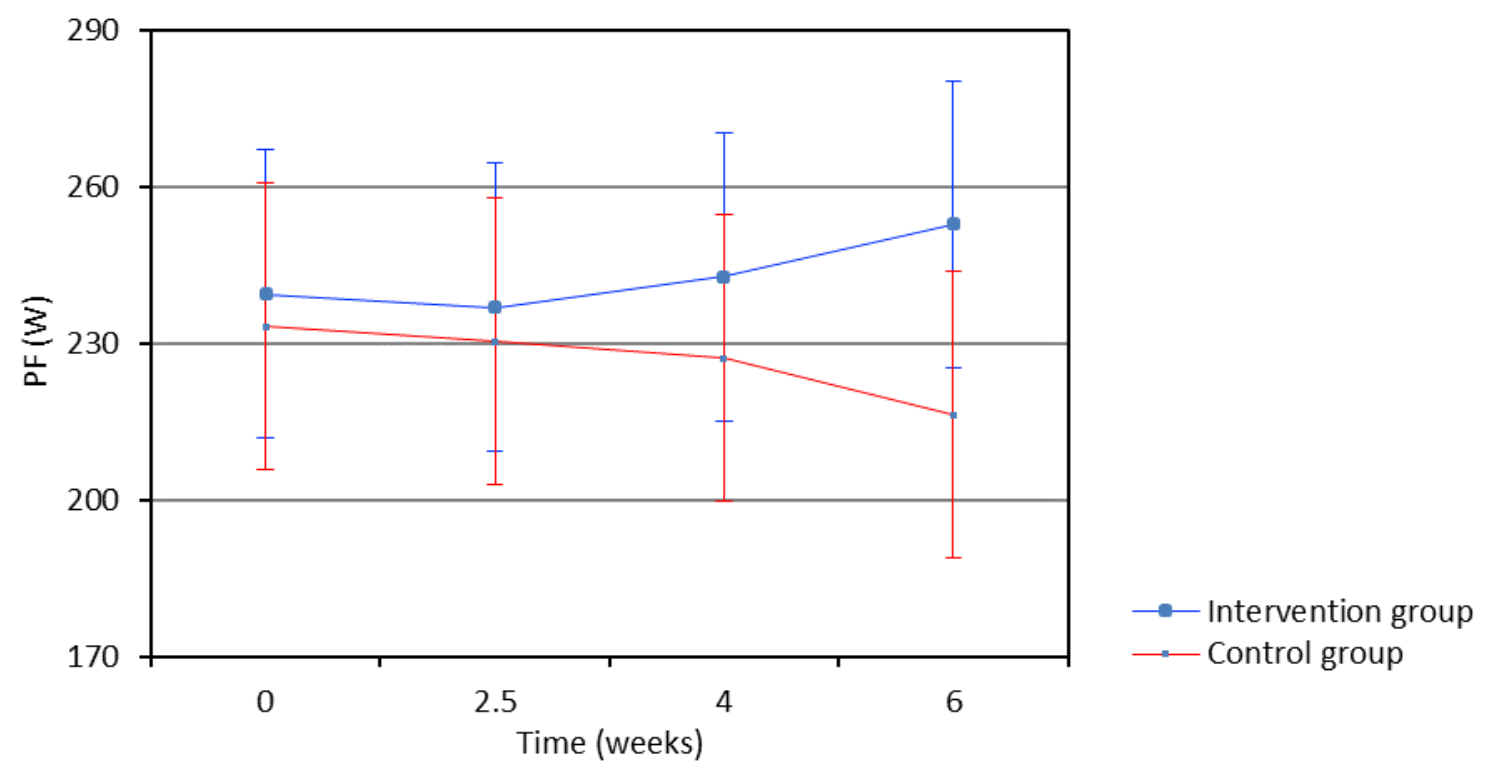

Figure 5

Graphical Presentation of Change over Time in Maximum paddling force (PF) in Watts

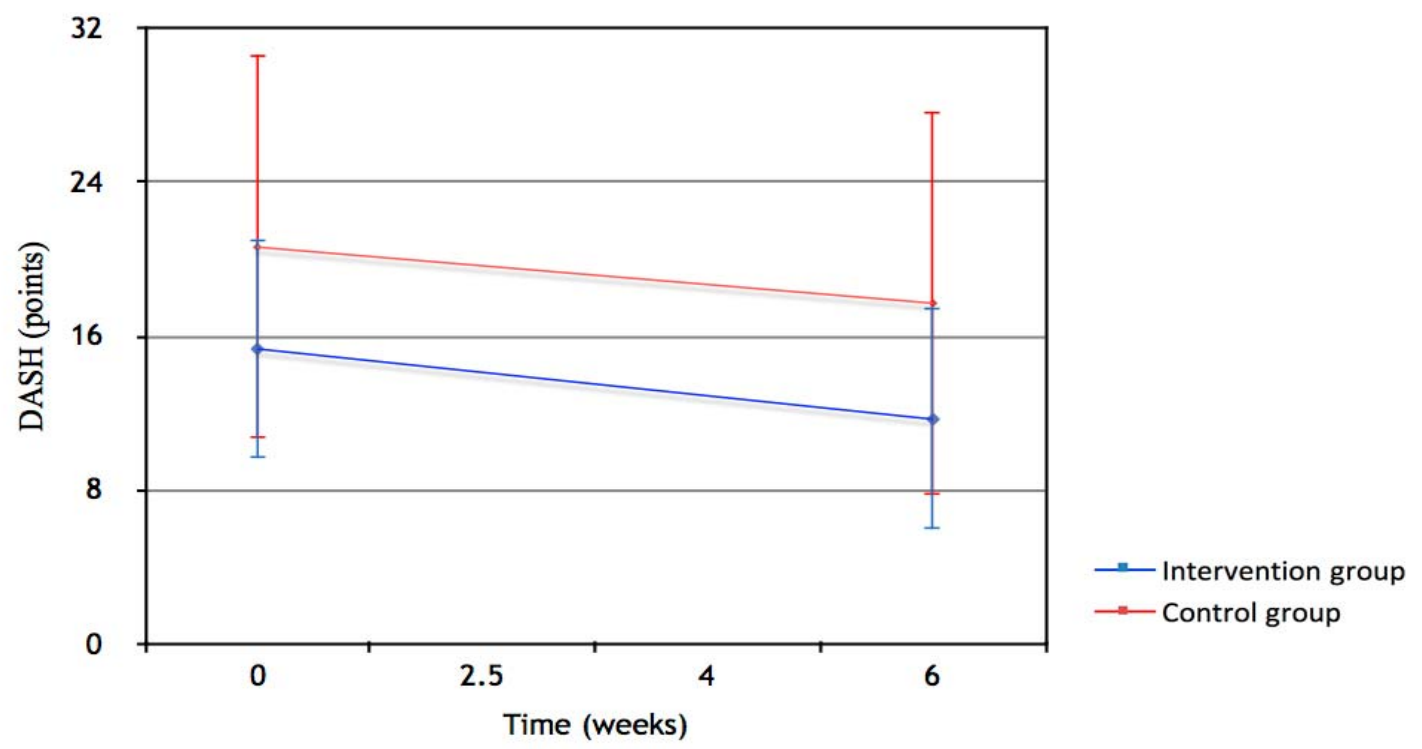

Figure 6

Graphical Presentation of Change over Time in the DASH Questionnaire

\section{Discussion}

We examined whether the use of a Dynamic Neuromuscular Stabilization (DNS) (Kolar and Safarova, 2013) exercise approach promoting optimal trunk and shoulder girdle stabilization would positively influence PF and painful upper quarter syndromes in a sample of flatwater kayakers. After six weeks of training, a significant increase in PF was observed in the DNS intervention group compared to the control group performing exercises as usual. This gain in PF was expressed as partial eta-squared of 0.15 , 
which corresponds to Cohen's d of 0.85 and represents a large effect size. A decrease in the self-reported level of pain was also observed, but it was matched by pain reduction in the control group, resulting in a non-significant net gain in pain reduction in the intervention group relative to the control group.

The PF increase resulting from integration of DNS within traditional training may positively influence athletic performance. It is possible that the observed $5.6 \%$ increase in maximum PF in the intervention group over the control group may result in a faster race time. However, there are also other aspects of competitive performance than muscle strength and speed. The DNS approach is not the type of technique that would train muscle strength directly. Rather, it focuses on muscle coordination and proper core stabilization as prerequisites for developing an optimal movement pattern, in this case a paddling movement pattern. Current research literature addresses the importance of the deep spinal stabilizing muscle system for performance (Bouche et al., 2011; Kim et al., 2010; Watanabe et al., 2010). However, the influence of 'deep muscles' goes beyond spinal and extremity joint stability. The DNS approach emphasizes the integrated spinal stabilization system (ISSS) through which the entire body works together to stabilize and move. The most important muscles forming the ISSS are the diaphragm, the pelvic floor, the entire abdominal wall, and the short intersegmental spinal musculature (i.e., $\mathrm{m}$. multifidus lumborum) (Frank et al., 2013). These structures work together to generate pressure within the abdomen (i.e., intra-abdominal pressure [IAP]), which interacts with the spinal extensors to maintain the spine in a stable and elongated position necessary for optimal movement function. Core stabilization needs to meet the demands of whatever task the athlete performs. Whether paddling or deadlifting heavy weights, the movement is anchored by IAP (Rintala et al., 2016). DNS exercises train the ISSS to improve coordination and, in turn, to allow for an effective movement and peak sport performance.

The intervention group was instructed to apply exercises in four DNS-based developmental positions that we considered to be especially demanding with respect to trunk stabilization with a specific focus on shoulder girdle stability and muscle coordination. At first the subjects only stayed in the static exercise positions (Figure 1-4), focusing on proper joint position and muscle coordination. They could maintain each position only as long as the proper postural stereotype (corresponding with optimal developmental pattern) was utilized. Once a deviation from the optimal stereotype as a result of fatigue or pain occurred the exercise was stopped and, after a short break, the exercise in another position was started. Later, once the subject performed a static exercise in each position properly, a locomotion movement from one position to another was trained. For example, a movement from side sitting to quadruped position back and forth, movement from a higher to a deeper squat down and up, etc. Not the duration but the quality of exercise was heavily stressed during each session. Each exercise session took between 20 to 30 minutes a day, i.e., a relatively small portion of daily physical training. Still, it seemed that such short but regular coordination training improved not just the muscle strength (PF), but it also decreased painful upper quarter syndromes illustrated by DASH questionnaire improvement.

The pre- to post-intervention differences in $\mathrm{PF}$ were driven by both the increase in $\mathrm{PF}$ in the intervention group as well as the decrease in PF of the control group after the 6 weeks of the study. We may speculate that traditional off-season sport training that puts the main focus on progressive weight training, ergometer paddling and general sport training (running, swimming) may result in compromised postural function and core stability, as well as relatively poor adaptation to progressively increasing training loads.

Based on a graphical presentation in Figure 3, it appears that the large gains in performance in the DNS training group occurred between weeks 4 and 6 . Therefore, it appears that to fully utilize the benefits of DNS with respect to paddling force, integration of DNS to traditional kayak training should be applied for at least 6 weeks.

This is not the first study pointing to the important influence of core training on extremity function, strength and sport performance. Core strength has the potential to prevent injuries and increase the length of athletic career (Kline et al., 2013). Sharrock et al. (2011) proposed a link 
between core stability tests and athletic performance tests. In a study published by StrayPedersen et al. (2006), Sling Exercise Training (SET) focusing on core stability in soccer players significantly increased the ball velocity of the participants at one-step maximal velocity kicking. SET core stability training in closed kinetic chains increased maximum throwing velocity in handball players (Saeterbakken et al., 2011). Exercising in close versus open kinetic chains is another aspect to be considered. Albeit some sports utilize mainly one type of activity, i.e., movement in a close or open kinetic chain, training both stereotypes based on optimal core stabilization should be a regular part of any athletic training. For example, Prokopy et al. (2008) demonstrated a positive influence of core training coupled with a closed-kinetic chain on performance variables in softball players. Although softball throwing is an open-chain movement, closed-kinetic chain resistance training significantly improved throwing velocity by boosting shoulder strength and power in softball players, whereas exercise in open-chain did not induce significant changes in power and throwing velocity (Prokopy et al., 2008). In our study, the prescribed DNS-based exercise trained kinetic chains in upper and lower extremities with closed kinetic chain predominance. Yet it is important to note that, at all times, a proper core stabilization pattern was heavily emphasized over actual training of extremity movement or locomotion across exercise positions. Therefore, there is a reason to believe that training the proper core stabilization pattern was likely the main facilitator of the gain in PF in the intervention group.

Kayak paddling includes a contralateral movement pattern. When the left arm works in a closed kinetic chain, the right leg works simultaneously in a closed chain and vice versa. Therefore, the intervention group subjects were specifically instructed to train developmental kinesiology positions emphasizing a contralateral extremity support function. Kayakers routinely strengthen trunk stability in the frontal plane by performing sit-ups. However, during a kayak stroke, the trunk and the spine must rotate. If core stabilization is insufficient, the trunk and spine deviate in the frontal plane instead of segmental spinal rotation and postural scoliosis occurs with every stroke. This aspect is often overlooked. In this study we instructed the intervention group subjects to train rotation movement from side sitting (Figure 2) to a quadruped position (Figure 1) to train core stabilization in both the frontal and sagittal planes.

Developmentally based exercise positions in this study did not directly relate to any standard flatwater kayak training and performance. Still it resulted in increased PF and decreased shoulder pain (albeit a largely similar decrease in pain was observed in the control group). This corresponds with observation of other authors who also found improved sport performance and reduced pain by training aspects that differed from sport specific stereotypes (Prokopy et al., 2008; Saeterbakken et al., 2011; Stray-Pedersen et al., 2006).

In our study, we did not find a significant group-by-time interaction in DASH scores $(\mathrm{F}[1,18]$ $=0.12, p=.731$ ) (Figure 2), suggesting a lack of an effect of the intervention on pain. Available literature points to the relationship between insufficient core stability and painful syndromes in the athletic population suggesting specific core stability exercises to reduce shoulder pain resulting from excessive sport exposure (Bak, 2010; Heinlein and Cosgarea, 2010; Reeser et al., 2010). Ezechieli et al. (2013) warn that sports specific training itself does not lead to balanced trunk musculature and core stability, but conversely, may cause muscle imbalance that can trigger pain syndromes. Some authors suggest core training to avoid shoulder pain (Hutchinson and Ireland, 2003; Tate et al., 2012), however, existing evidence that such exercises are effective is not strong.

The intervention group reported reduced pain on two tasks in particular: "place an object on a shelf above your head" and "change a light bulb over head". This may be an important aspect for training. Painless movement above the head during paddling has the potential to increase PF of the contralateral arm during the stroke as it causes greater boat propulsion. Pain reduction during overhead work may allow the kayaker to paddle intensively for a longer period of time with less risk of shoulder girdle repetitive strain injury.

There are some limitations of this study. The study was not blinded and both intervention 
and control groups consisted of a relatively small sample of participants. Also, only four positions based on the DNS concept were utilized in the intervention group. However, we can speculate that a greater number of exercises could result in greater PF gains and pain reduction. Another limitation is a certain inconsistency in DNS training. In DNS, the quality of exercise performance is critical, not the quantity (i.e., the number of repetitions). The subjects were instructed to maintain a certain position or to repeat the movement only as long as the optimal stereotype was promoted. As soon as any deviation from the ideal stereotype occurred, the participants were instructed to terminate the exercise. Therefore, both the length of each DNS session and a number of repetitions were somewhat different for each participant and each session. Larger, blinded experiments including more exercise positions and closer supervision are necessary to ascertain the utility of specific core stabilization exercise with regard to sports performance and painful musculoskeletal syndromes. Finally, some control group participants experienced decline in PF despite continuing to train as usual. However, our post- hoc analyses suggested that this decline was not the main cause of the statistically significant improvement in the intervention group over the control group.

\section{Practical implications}

Our findings suggest that incorporating the DNS approach into traditional flatwater kayak training may lead to positive gains in maximum PF. The gains in PF are most likely the result of improved trunk and shoulder girdle stabilization. This is crucial for the prevention of athletic injuries and for optimal performance. We can speculate that the benefits of the DNS approach are more widespread than it is presented in this study, possibly extending to other physical functions and other sports. Future research should examine this idea.

\section{Conclusions}

Our findings suggest that incorporating a DNS-based exercise approach into regular kayak training may promote optimal trunk and shoulder girdle stabilization, whereby increasing maximum PF.

\section{Acknowledgements}

This study was supported by the foundation Movement without Help, Prague, Czech Republic and by scientific program PROGRES Q41 and Rehabilitation Prague School and by SVV 2018 - 260346.

\section{References}

Anderson B, Anderson J. Stretching. 30th anniversary ed. Bolinas, Calif: Shelter Publications; 2010

Bak K. The practical management of swimmer's painful shoulder: etiology, diagnosis, and treatment. Clin J Sport Med Off J Can Acad Sport Med, 2010; 20(5): 386-390 doi:10.1097/JSM.0b013e3181f205fa

Bouche KGW, Vanovermeire O, Stevens VK, Coorevits PL, Caemaert JJ, Cambier DC, Verstraete K, Vanderstraeten GG, Danneels LA. Computed tomographic analysis of the quality of trunk muscles in asymptomatic and symptomatic lumbar discectomy patients. BMC Musculoskelet. Disord, 2011; 65(12)

Brolinson PG, Smolka M, Rogers M, Sukpraprut S, Goforth MW, Tilley G, Doolan KP. Precompetition manipulative treatment and performance among Virginia Tech athletes during 2 consecutive football seasons: a preliminary, retrospective report. J Am Osteopath Assoc, 2012; 112(9): 607-615

Ezechieli M, Siebert CH, Ettinger M, Kieffer O, Weißkopf M, Miltner O. Muscle strength of the lumbar spine in different sports. Technol Health Care Off J Eur Soc Eng Med, 2013; 21(4): 379-386 doi: 10.3233/THC130739

Fiore DC, Houston JD. Injuries in whitewater kayaking. Br J Sports Med, 2001; 35(4): 235-241

Frank C, Kobesova A, Kolar P. Dynamic neuromuscular stabilization \& sports rehabilitation. Int J Sports Phys 
Ther, 2013; 8(1): 62-73

Hagemann G, Rijke AM, Mars M. Shoulder pathoanatomy in marathon kayakers. Br J Sports Med, 2004; 38(4): 413-417 doi: 10.1136/bjsm.2002.003699

Heinlein SA, Cosgarea AJ. Biomechanical Considerations in the Competitive Swimmer's Shoulder. Sports Health, 2010; 2(6): 519-525 doi: 10.1177/1941738110377611

Hensel P, Perroni MG, Leal Junior ECP. Musculoskeletal injuries in athletes of the 2006 season's Brazilian women's speed canoeing team. Acta Ortop Bras, 2008; 16(4): 233-237 doi: 10.1590/S141378522008000400009

Hill J, Leiszler M. Review and role of plyometrics and core rehabilitation in competitive sport. Curr. Sports Med Rep, 2011; 10:345-351

Hutchinson MR, Ireland ML. Overuse and throwing injuries in the skeletally immature athlete. Instr Course Lect, 2003; 52: 25-36

Imai A, Kaneoka K, Okubo Y, Shiraki, H. Effects of two types of trunk exercises on balance and athletic performance in youth soccer players. Int J Sports Phys Ther, 2014; 9: 47-57

Kim K, Lee SK, Kim YH. The biomechanical effects of variation in the maximum forces exerted by trunk muscles on the joint forces and moments in the lumbar spine: a finite element analysis. Proc Inst Mech Eng, 2010; 224: 1165-1174

Kline JB, Krauss JR, Maher SF, Qu X. Core strength training using a combination of home exercises and a dynamic sling system for the management of low back pain in pre-professional ballet dancers: a case series. J Dance Med Sci Off Publ Int Assoc Dance Med Sci, 2013; 17(1): 24-33

Kobesova A, Kolar P. Developmental kinesiology: three levels of motor control in the assessment and treatment of the motor system. J Bodyw Mov Ther, 2014; 18(1): 23-33 doi: 10.1016/j.jbmt.2013.04.002

Kobesova A, Valouchova P, Kolar P. Dynamic Neuromuscular Stabilization: Exercises based on developmental kinesiology models. In: Functional Training Handbook, Philadelphia: Wolters Kluwer Health/Lippincott Williams \& Wilkins; 2014: 25-51

Kolar P, Safarova M. Dynamic Neuromuscular Stabilization. In: Clinical Rehabilitation, Prague: Rehabilitation Prague School; 2013: 262-265

Lust KR, Sandrey MA, Bulger SM, Wilder N. The effects of 6-week training programs on throwing accuracy, proprioception, and core endurance in baseball. J Sport Rehabil, 2009; 18: 407-426

Mei-Dan O, Carmont MR. Adventure and Extreme Sports Injuries Epidemiology, Treatment, Rehabilitation and Prevention, London; New York: Springer; 2013

http://www.springerlink.com/openurl.asp?genre=book\&isbn=978-1-4471-4362-8. Accessed October 8, 2015

Pelham TW, Holt LE, Stalker RE. The etiology of paddler's shoulder. Aust J Sci Med Sport, 1995; 27(2): 43-47

Prokopy MP, Ingersoll CD, Nordenschild E, Katch FI, Gaesser GA, Weltman A. Closed-kinetic chain upperbody training improves throwing performance of NCAA Division I softball players. J Strength Cond Res Natl Strength Cond Assoc, 2008; 22(6): 1790-1798. doi: 10.1519/JSC.0b013e318185f637

Reeser JC, Joy EA, Porucznik CA, Berg RL, Colliver EB, Willick SE. Risk factors for volleyball-related shoulder pain and dysfunction. PM R, 2010; 2(1): 27-36 doi: 10.1016/j.pmrj.2009.11.010

Rintala M, Ulm R, Jezkova M, Kobesova A. Czech Get-up. NSA Coach, 2016; 3: 30-38 
Rivera CE. Core and Lumbopelvic Stabilization in Runners. Phys Med Rehabil Clin N Am, 2016; 27: 319-337

Saeterbakken AH, van den Tillaar R, Seiler S. Effect of core stability training on throwing velocity in female handball players. J Strength Cond Res Natl Strength Cond Assoc, 2011; 25(3): 712-718. doi: 10.1519/JSC.0b013e3181cc227e

Sharma A, Geovinson SG, Singh Sandhu J. Effects of a nine-week core strengthening exercise program on vertical jump performances and static balance in volleyball players with trunk instability. J Sports Med Phys Fitness, 2012; 52: 606-615

Sharrock C, Cropper J, Mostad J, Johnson M, Malone T. A pilot study of core stability and athletic performance: is there a relationship? Int J Sports Phys Ther, 2011; 6(2): 63-74

Stray-Pedersen JI, Magnusen R, Kuffel E, Seiler S, Katch FI. Sling Exercise Training Improves Balance, Kicking Velocity, and Torso Stabilisation Strength in Elite Soccer Players: 1611. Med Sci Sports Exerc, 2006; 38(Supplement): S243. doi: 10.1249/00005768-200605001-01072

Tate A, Turner GN, Knab SE, Jorgensen C, Strittmatter A, Michener LA. Risk factors associated with shoulder pain and disability across the lifespan of competitive swimmers. J Athl Train, 2012; 47(2): 149158

Watanabe S, Kobara K, Ishida H, Eguchi A. Influence of trunk muscle co-contraction on spinal curvature during sitting cross-legged. Electromyogr Clin Neurophysiol, 2010; 50: 187-192

\section{Corresponding author:}

\section{Pavel Davidek, MPT}

Faculty of Physical Education and Sport

Charles University in Prague

José Martího 31

162 52, Prague 6

Czech Republic

Tel: +420737760734; Fax:+420 224439220

E-mail address: padavidek@gmail.com 